\title{
EMERGENCY HEALTHCARE PROVIDERS PERCEPTION OF WORKPLACE DANGERS IN THE POLISH EMERGENCY MEDICAL SERVICE: A MULTI-CENTRE SURVEY STUDY
}

\author{
Tomasz Klosiewicz ${ }^{1} \oplus$, Radoslaw Zalewski ${ }^{1} \oplus$, Marek Dabrowski ${ }^{2} \oplus$, Karolina Klosiewicz ${ }^{3}$, \\ Andrzej Rut ${ }^{4} \odot$, Maciej Sip $^{1} \odot$, Agata Dabrowska ${ }^{1} \odot$, Michal Mandecki ${ }^{1} \odot$, \\ Radoslaw Stec ${ }^{1}{ }^{1}$, Michal Nowicki ${ }^{1} \odot$, Lukasz Szarpak ${ }^{5} \odot$ \\ ${ }^{1}$ Department of Medical Rescue, Poznan University of Medical Sciences, Poznan, Poland \\ ${ }^{2}$ Chair and Department of Medical Education, Poznan University of Medical Sciences, Poznan, Poland \\ ${ }^{3}$ Faculty of Health Sciences, Poznan University of Medical Sciences, Poznan, Poland \\ ${ }^{4}$ Department of Medical Rescue and Physiotherapy. Pomeranian Academy in Slupsk, Poland \\ ${ }^{5}$ Lazarski University, Warsaw, Poland
}

\begin{abstract}
INTRODUCTION: There are many risk factors that account for hazards in paramedics' and ambulance nurses' profession. Driving a vehicle, having contact with patients, making difficult medical decisions, doing night shifts and working in a stressful environment, all of those features negatively affect their health. The aim of the study was to evaluate paramedics' and ambulance nurses attitude towards personal safety, to assess their subjective feeling of danger, as well as identify types of hazards they experience.
\end{abstract}

MATERIAL AND METHODS: The study was carried out via a diagnostic survey method, an anonymous questionnaire. Among 572 responders there were nurses and paramedics, who work in non-physician medical rescue teams in Poland.

RESULTS: Most of the surveyed medics (40.5\%) have rated the level of danger of their occupation to 4 on a scale from 1 to 5 , with the greatest hazard being posed by patients under the influence of designer drugs. As many as $43 \%$ of medics have had back-related problems and $41 \%$ have suffered injuries at work. Notwithstanding, a majority of respondents have admitted that if they could plan their career again, they would choose the same profession.

CONCLUSIONS: Prehospital healthcare providers have generally rated their work as dangerous. More attention should be paid to teach first responders how to deal with aggression and how to handle stress. Efforts should be made to increase paramedics' and nurses' awareness about health problems related to shift work.

KEY WORDS: workplace violence; occupational risk factors; occupational stress; Emergency Medical Services; prehospital care; workplace safety

Disaster Emerg Med J 2019; 4(4): 166-172

\section{INTRODUCTION}

Prehospital healthcare providers who render specialized help in various life-threatening situations are burdened with great responsibility. Dynamically changing social and environmental conditions increase their stress levels. According to the International Agency for Research 
in Cancer, shift work is unavoidable because a paramedic must be available 24 hours a day, 365 days a year. Moreover, in 2007, shift work including nights has been classified as potentially carcinogenic to humans [1]. Prehospital healthcare providers are under constant professional risk, although their overriding principle is to act in safe conditions. Posttraumatic stress disorder (PTSD), as a result of multiple traumatic experiences related to suffering and death, can potentially affect everyone working in this profession $[2,3]$.

Prehospital healthcare providers often emphasize that cases involving children are extremely challenging, and place undue strain on their work. They are afraid of their reactions and identify their own children with the situation [4]. Number of PTSD cases varies from country to country [5]. Behavioural disorders, anxiety and depression lead to decreasing job satisfaction and professional burnout [6]. Stress can also be caused by a poor organization within a rescue team. Frequent employee rotation between different emergency service stations may cause problems with cooperation between paramedics [7]. In order to reach the scene, a paramedic or nurse, who works also as an ambulance driver, must often travel at high speeds, what increases the likelihood of an accident The most common cause of accidents is an excessive fatigue of providers, who are unable to maintain an adequate level of safety when driving to or from an event [8]. In recent years, aggression against medical rescuers has intensified, as confirmed by numerous media reports. Other hazards include contact with potentially infectious material and are sometimes linked with a physical location where help is being provided, e.g. high altitudes, slippery surfaces, aquatic environments, and many others [7].

The aim of this study was to identify the levels of this subjective sense of danger among ambulance nurses and paramedics, as well as define dangers themselves.

\section{Description of the study \\ MATERIAL AND METHODS}

A diagnostic survey method was employed. The research tool was a questionnaire survey. Among responders, there were paramedics and nurses with postgraduate training in emergency medicine and anaesthesiology and intensive care, working in non-physician MRTs in Greater Poland, West Pomeranian, Masovian and Podlesian provinces. A province is the highest level of administrative division in Poland. There are
16 provinces in the country. The voluntary and anonymous questionnaire, which consisted of 16 questions, has been completed by 572 respondents. Seven questions concerned metrics (gender, age, career length, stationing, daily dispatches, number of hours worked per day, number of hours worked per month, and frequency of encountering aggression). In question number 8 the respondents were asked to assess the degree of occupational hazards on a scale from 1 to 5 , with 1 representing the lowest, and 5 the highest level of danger. Questions number 9 and 10 rate the degree of threat to physical and mental health of the provider, on a scale from 0 to 5 , with 0 representing no hazard and 5 representing the highest hazard level. The remaining 6 questions were closed, with qualitative variables, as well as answers to questions, described by the number ( $\mathrm{n}$ ) and frequency (\%). The tool is the authors' own project, not validated at this moment. The daily number of dispatches, and risk assessment of the paramedic profession, as measurable variables, were described using basic parameters: arithmetic mean, standard deviation, median, minimum and maximum value. Statistical calculations were performed using STATISTICA 10 PL (StatSoft, Tulsa, OK, USA). A p-value $<0.05$ was accepted as statistically significant. Chi ${ }^{2}$ test for nonparametric variables, and multivariate ANOVA regression analysis for dependent variables assessing occupational hazards and evident exposures were performed.

\section{Description of the analysed groups}

A majority of the respondents were men - $81.8 \%$ ( $n=468)$, whereas women represented the remainder $18.2 \%(n=104)$. Paramedics constituted $85.2 \%$ ( $n=487,456$ males and 31 females) of the group and nurses $14.8 \%(n=85,12$ males and 73 females). Over half of the analysed group, $59.3 \%(n=339)$, was between 20 and 30 years old, while $29.4 \%(n=168)$ was $30-40$. The remaining $11.3 \%(n=65)$ was above 40 years old, and $1.2 \%$ $(n=7)$ was above 50 . Table 1 shows the frequency of responses to questions about career length, daily dispatches, number of workplaces, and frequency of encountering aggression during work.

\section{RESULTS}

The survey questionnaire has been distributed to a group of 800 paramedics working in medical rescue teams, $71.5 \%(n=572)$ of which have been completed. 


\begin{tabular}{|c|c|c|}
\hline Variable & $\mathrm{N}$ & $\%$ \\
\hline \multicolumn{3}{|c|}{ Hours worked (per month) } \\
\hline$<80$ & 10 & 1.7 \\
\hline 80-120 & 87 & 15.2 \\
\hline $160-240$ & 181 & 31.6 \\
\hline $240-320$ & 235 & 41.1 \\
\hline$>320$ & 59 & 10.4 \\
\hline \multicolumn{3}{|l|}{ Workplace } \\
\hline Countryside & 24 & 4.2 \\
\hline City $<10$ thousand residents & 55 & 9.6 \\
\hline City $10-20$ thousand residents & 92 & 16.1 \\
\hline City $20-50$ thousand residents & 69 & 12.1 \\
\hline City 50-100 thousand residents & 71 & 12.4 \\
\hline City $>100$ thousand residents & 332 & 45.6 \\
\hline \multicolumn{3}{|l|}{ Career length } \\
\hline$<1$ year & 39 & 6.8 \\
\hline $1-5$ years & 203 & 35.5 \\
\hline $5-10$ years & 221 & 38.6 \\
\hline$>10$ years & 109 & 19.1 \\
\hline \multicolumn{3}{|c|}{ Daily dispatches } \\
\hline $1-5$ & 114 & 19.3 \\
\hline $6-10$ & 286 & 50.0 \\
\hline $11-15$ & 99 & 17.3 \\
\hline$>15$ & 73 & 13.4 \\
\hline \multicolumn{3}{|c|}{ How often do you encounter aggressive patients? } \\
\hline I have not met an aggressive patient & 19 & 3.3 \\
\hline A few times a year & 71 & 12.4 \\
\hline A few times a month & 191 & 33.4 \\
\hline A few times a week & 251 & 43.9 \\
\hline Every day, sometimes multiple times & 40 & 7.0 \\
\hline
\end{tabular}

None of the respondents has rated their profession as completely safe. The average rating of the danger level on a $1-5$ scale was $3.6 \pm 0.91$. Most of the respondents $(40.5 \%)$ assessed the danger as $4 / 5$ (high level of danger). In the multivariate analysis for the dependent variable evaluating the danger of the profession ( $1-5$ scale), career length over 5 years has emerged as an independent variable. Multivariate regression has shown that providers with a career length $>5$ years have assessed the danger level 1.132 times higher $\left(p<0.001, R^{2}=0.181\right)$.
Table 2. The average rating of threats to health and life ranked from highest to lowest

\begin{tabular}{|l|c|c|}
\hline \multicolumn{1}{|c|}{ Threats } & $\begin{array}{c}\text { Average } \\
\text { rate }\end{array}$ & $\begin{array}{c}\text { Standard } \\
\text { deviation }\end{array}$ \\
\hline $\begin{array}{l}\text { Patient under the influence of } \\
\text { designer drugs }\end{array}$ & 4.3 & 1.11 \\
\hline Patient under the influence of alcohol & 3.9 & 1.00 \\
\hline $\begin{array}{l}\text { Patient suffering from mental } \\
\text { disorders }\end{array}$ & 3.7 & 1.17 \\
\hline $\begin{array}{l}\text { Psychological burden caused by low } \\
\text { earnings }\end{array}$ & 3.6 & 1.39 \\
\hline $\begin{array}{l}\text { Patient under the influence of classic } \\
\text { drugs }\end{array}$ & 3.5 & 1.22 \\
\hline $\begin{array}{l}\text { Patient suffering from diseases } \\
\text { transmitted by body fluids (e.g. HIV, } \\
\text { viral hepatitis) }\end{array}$ & 3.4 & 1.43 \\
\hline Patients' violence & 3.3 & 1.30 \\
\hline Bystanders' violence & 3.1 & 1.34 \\
\hline $\begin{array}{l}\text { The risk of participation in an } \\
\text { ambulance crash }\end{array}$ & 2.9 & 1.51 \\
\hline $\begin{array}{l}\text { Psychological burden caused by } \\
\text { number of work hours }\end{array}$ & 2.8 & 1.49 \\
\hline $\begin{array}{l}\text { Psychological burden caused by night } \\
\text { shift }\end{array}$ & 2.4 & 1.53 \\
\hline Risk of a burnout syndrome & 2.4 & 1.55 \\
\hline Psychological burden caused by death & 2.1 & 1.49 \\
\hline Animals attacks & 1.43 \\
\hline
\end{tabular}

As the most threatening situation respondents indicated interaction with patients under the influence of designer drugs ( $4.3 \pm 1.11$ points), followed by patients under the influence of alcohol (3.7 \pm 1.0 points). The average rating of threats to health and life lowest was shown in Table 2.

The most aggressive patients were those under the influence of designer drugs $(4.4 \pm 0.94)$ and alcohol (3.8 \pm 1.02$)$, followed by people breaking the law (3.63), people under the influence of classic drugs (3.6), and people suffering from mental disorders (3.4). The lowest level of aggression among the listed group was displayed by people in shock, with an average score of $2.0 \pm 1.17$.

The definition of "evident exposure" was described as contact with blood or other potentially infectious material, with an open wound or wound caused by the material. According to this definition, $39.3 \%$ of respondents have declared evident exposure, and $24.1 \%$ of respondents have declared multiple instances of evident exposure. 
In multivariate analysis for a dependent variable, which most accurately assessed the occurrence and intensity of evident exposure, career length $>5$ years has been found to be the most independent variable. It has been shown that medics with career lengths over five years have declared more frequent occurrence and exacerbation of evident occupational exposure 2.528 times higher $\left(p<0.001, R^{2}=0.256\right)$.

The results show that $41.5 \%$ of respondents employed in the EMS have been affected by health problems requiring out-patient or in-patient care. There were statistically significant differences in terms of age ( $>30$ years vs. $<30$ years; $p<0.001$ ), career length ( $>10$ years vs. $<10$ years, $p<0.001$ ), and patient aggression (several times a week vs. several times a month; $p=0.042$ ).

The survey also analysed factors that could affect the responses to the question regarding an occupationally acquired spinal injury. There were statistically significant differences in the number of working hours ( $>160 \mathrm{~h}$ vs. $<160 \mathrm{~h} ; \mathrm{p}=0.017$ ) and patient aggression (several times and week vs. several times a month; $\mathrm{p}<0.001$ ).

Beyond that, $43 \%$ of respondents have indicated that they have had an occupationally acquired spinal injury at some point during their career.

Most of the respondents (69.1\%), if given the option today, would continue to choose to work as paramedics or ambulance nurses and $19.1 \%$ would not (and $2.8 \%$ of those definitely would not choose to be a paramedic again). The remaining $11.8 \%$ were not able to answer the question.

\section{DISCUSSION}

The researchers attempted to answer the question of how paramedics assess the safety of their profession, and what factors may affect their perception of danger.

Providers have assessed the danger of their profession, on average, as 3.6 on a five-point scale. None of the factors assumed by the authors contributed to the perception of work safety, namely, regardless of workload and experience, hazards are perceived in the same way. The individuals who have responded to the questionnaire considered interacting with people under the influence of various psychoactive substances as the most dangerous to their health.

Psychoactive substances which are not included in the list of controlled substances, i.e. legal high (a.k.a. smart drugs or designer drugs) pose the biggest issue. The scale of this problem is especially pronounced in large cities with entertainment facilities in the form of clubs and discos. The most popular psychoactive substances identified by the organs of the State Sanitary Inspection are cannabinoids, cathinones ( $\beta$-keto-amphetamines), and phenylethylamines. In 2014, there were 1079 reported cases of designer drugs poisonings, and 2513 in 2015, with an apparent growing trend in a number of cases reported each month. On a national scale, the rate of poisoning by alternative substances, in 2014, was 6.53 cases per 100-thousand, which is 2.45 times higher than the rate in 2013. People between the age of 16 and 24 made up the largest group of those affected [9]. A state of intoxication is also related to the increasing occurrence of violent acts. According to available publications, it is known that paramedics are confronted with aggression in various forms, both verbal and non-verbal, but it is less often mentioned that they are subject to sexual violence, as well. A paper published in 2002 showed that the greatest number of paramedics experienced aggression in their workplace once every quarter-year [10]. Another study conducted in the hospital emergency department (ED) showed that the frequency of aggression directed against staff was on average five cases a week, and that the number was particularly high during night shifts. The study by Rudnicka-Drożdżak et al. showed that over $90 \%$ of ED staff have dealt with patient aggression at some point in their careers [11]. Moreover, a study by Frydysiak et al. indicated that $50 \%$ of ED staff members declared that the aggressive patient they last dealt with was also intoxicated [12]. Petzall et al. proved that $66 \%$ of ambulance personnel in Sweden experienced threats or violence and the most common form was physical violence (pushes, punches, kicks and bites). The perpetrators were also patients under the influence of alcohol and drugs [13]. The results, however, are far more disturbing, as most of the study's respondents have been encountering this problem even several times every week. The increased incidence of aggression seems to be a consequence of high accessibility of drugs and alcohol. Aggressive behaviours can also be triggered by suffering and anxiety caused by worrying about the health of a loved one. Perhaps one of the reasons why paramedics are often a target of aggression is that they represent a crucial first layer of contact within the healthcare system. Another reason might 
be that frequently patients need to wait very long in order to have a doctor appointment, usually due to a large number of patients and hospital being short-staffed.

According to the authors' research, providers assessed the danger of being involved in an accident as 2.9 points out of 5 , meaning less than in the case of the previously discussed aggression. These accidents are often caused by excessive speed, bravado, inattention, or the determination of the ambulance driver to reach a victim as quickly as possible [14]. According to data published by the Central Institute for Labour Protection, paramedics usually suffered from lower and upper limbs (mainly fingers) injuries, as well as neck, back and spine damages. Moreover, paramedics pointed out that the most physically strenuous activity was cardiopulmonary resuscitation, whereas the most mentally straining factors were unsatisfactory salary and providing medical service in accidents, in which children were the victims [15]. This is consistent with this study's results, which show that low salaries are one of the leading causes of increased mental stress. At this point, it is worth to mention that due to low earnings, healthcare providers take up additional work in emergency departments or in education field. Over half of respondents worked over 240 hours a month and $10 \%$ more than 320 hours. We find this data disquieting. It may lead to faster and more frequent burnout as well as health problems in the future. Employees' fatigue can also influence efficiency and accuracy of their decisions.

Our results showed that over $40 \%$ of responders had a work-related spinal injury or other medical problems, which required medical intervention. In a study published by Rahimi et al., in 2014, a group of 180 nurses working in ED indicated that over $70 \%$ of them have experienced some type of work-related back pain. Additionally, it has been proven that there is a correlation between the development of depression, increased stress levels, decreased job satisfaction and the occurrence of pain [16]. It is worrisome that in this study, long working hours and the possibility of professional burnout were placed so low on the list of potential dangers.

Disorders of biological rhythms associated with night-time work affect mood, well-being, sleep, the cardiovascular system, the digestive tract, hormonal levels, and tumour development. Melatonin-related disorders and elevated inflammatory markers have also been reported [17]. People working in such a system also have an increased incidence of obesity, elevated triglycerides, lowered HDL cholesterol, and, in women over 60, an increased incidence of glucose intolerance. These metabolic disorders are risk factors for cardiovascular disease. However, because these discrepancies do not give any early symptoms when complications do arise, they are often severe and may significantly affect work capacity [18]. Interestingly, a shorter sleep time $(\leq 6$ hours per day) was associated with a lower risk of developing melanoma ( $\mathrm{HR}=0.68,95 \% \mathrm{Cl}, 0.46$ to 0.98 ) and basal cell carcinoma ( $\mathrm{HR}=0.93,95 \% \mathrm{Cl}, 0.86$ to 1.00) compared with the most commonly reported 7 hours [19]. In one of the studies published in 2017, the authors found a significant difference in the risk of breast cancer in the group of women with 20 years or more of shift work compared with those who never performed shift work [20]. Danish nurses working night and evening shifts had increased risk for diabetes [21]. Among registered nurses, longer duration of rotating night shift work was associated with a significant but small absolute increase in CHD (chronic heart disease) risk [22]. What might be interesting, the participants in this study rated night shift work as a threat to health at 2.8. This information seems to be alarming for us. The majority of respondents were between 20 and 30 years old, hence they may not experience health problems yet. Nevertheless, information campaigns promoting health and hygiene could prevent any potential diseases among paramedics in the future.

The results of a Polish study published in 2011 are especially interesting in this regard. The authors of that study pointed out that $100 \%$ of their respondents have experienced some sort of somatic symptoms associated with stress. Irritation, headaches, sleep disturbances, and abdominal pain were among the most commonly reported. Additionally, duodenal ulcers were present in $6 \%$ of the paramedics. The symptoms were more frequent for paramedics with a longer career length, and those older than 40, which confirmed the chronic nature of the stressors. Uncontrolled outbursts of anger, screaming, or other negative emotional behaviour was also reported by $19 \%$ of the paramedics. Although many young people participated in the study, $20 \%$ of the respondents reported suffering from professional burnout. It was also emphasized that in order to alleviate stress, respondents have turned to tobacco products, alcohol, designer drugs, and other pharmacological agents [23]. The stressor load is further exacerbated 
by the fact that there is an increased risk of causing car accidents and making more mistakes in general between 1 and 3 AM when the physical response to stimuli is most delayed. This is also confirmed by the fact that the common cause for the accident was careless behaviour of a paramedic [23, 24].

Also worrying is the fact that nearly half of all respondents have been exposed to infectious material. Although the number of HBV (hepatitis B virus) and HCV (hepatitis $C$ virus) infections has dropped by $90 \%$ since 1999 [25], there is still a risk of infection. One of the ways to enhance safety while working with potentially infectious biological material is to use double gloves. However, wearing two pairs of gloves has also been shown to decrease the precision of medical procedures [26]. In studies by Braczkowska et al., paramedics made up only $3.21 \%$ of the total number of health workers who had undergone occupational exposure, while $65 \%$ were nurses and $17.5 \%$ physicians. Yilmaz found, that $41.3 \%$ of work-related injuries have occurred inside the cruising ambulance [27]. There are plenty of life-saving procedures that must be done on the way to ED. Those are for example: maintaining manual airway patency, ventilation or drug administration.

Another important aspect is the risk of exposure to carbon monoxide, which is elevated in the wintertime. There is also a risk of exposure as a result of various technological processes [28], however, knowledge of the chemical reactions or processes that result in the production of carbon monoxide is not required of MRT members. Because of this, ambulances in some cities now carry carbon monoxide detectors, although this equipment is not yet considered mandatory.

Training in communication skills improves the confidence of staff in dealing with aggression. Baby et al. found that staff training that focuses on communication skills is a possible prevention strategy for aggression [29]. Nowadays medical simulation is found to be a very efficient method of training in wide aspect, either medical or communications skills [30]. To improve providers' safety, their educational programme should encompass classes with a high fidelity simulation that imitates dealing with aggressive patients.

\section{CONCLUSIONS}

Prehospital healthcare providers are exposed to an array of factors, which may pose threats to their health and life, even though the overriding principle of the occupation states that personal safety is a number one priority. This article represents only a preliminary to a wider subject matter of work safety in prehospital healthcare. Efforts should be made in order to enhance the level of security and to reduce the number of working hours. The authors' proposal contains postgraduate courses in self-defence and in coping with stress, both based on high fidelity simulation method. It might be beneficial for ambulance crew members to raise their awareness concerning long-term resonance of extensive working hours and shift work.

\section{REFERENCES}

1. International Agency for Research on Cancer (IARC). The Grants Register 2019. 2018: 411-412, doi: 10.1007/978-1-349-95810-8_652.

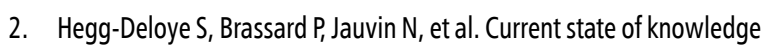
of post-traumatic stress, sleeping problems, obesity and cardiovascular disease in paramedics. Emerg Med J. 2014; 31(3): 242-247, doi: 10.1136/emermed-2012-201672, indexed in Pubmed: 23314206.

3. Luftman K, Aydelotte J, Rix K, et al. PTSD in those who care for the injured. Injury. 2017; 48(2): 293-296, doi: 10.1016/j.injury.2016.11.001, indexed in Pubmed: 27871770.

4. Guise JM, Hansen M, O'Brien $K$, et al. Emergency medical services responders' perceptions of the effect of stress and anxiety on patient safety in the out-of-hospital emergency care of children: a qualitative study. BMJ Open. 2017; 7(2): e014057, doi: 10.1136/ bmjopen-2016-014057, indexed in Pubmed: 28246139.

5. Koenen KC, Ratanatharathorn $\mathrm{A}, \mathrm{Ng} \mathrm{L}$, et al. Posttraumatic stress disorder in the World Mental Health Surveys. Psychol Med. 2017; 47(13): 2260-2274, doi: 10.1017/50033291717000708, indexed in Pubmed: 28385165.

6. Iranmanesh S, Tirgari B, Bardsiri HS. Post-traumatic stress disorder among paramedic and hospital emergency personnel in southeast Iran. World J Emerg Med. 2013; 4(1): 26-31, doi: 10.5847/ wjem.j.1920-8642.2013.01.005, indexed in Pubmed: 25215089.

7. Weaver MD, Patterson PD, Fabio A, et al. An observational study of shift length, crew familiarity, and occupational injury and illness in emergency medical services workers. Occup Environ Med. 2015; 72(11): 798-804, doi: 10.1136/oemed-2015-102966, indexed in Pubmed: 26371071.

8. Smith N. A National Perspective on Ambulance Crashes and Safety. Guidance from the National Highway Traffic Safety Administration on ambulance safety for patients and providers. EMS World. 2015; 44(9): 91-94, indexed in Pubmed: 26521402.

9. The report of the Chief Sanitary Inspectorate of new psychotropic substances. Warsaw, 2015.

10. Suserud BO, Blomquist $M$, Johansson I. Experiences of threats and violence in the Swedish ambulance service. Accid Emerg Nurs. 2002; 10(3): 127-135, indexed in Pubmed: 12443033. 
11. Rudnicka-Drożak E, Misztal-Okońska P, Młynarska M. Opinions of the hospital emergency department workers on the subject of providing medical assistance to patients with alcohol poisoning — a preliminary report. Probl Hig Epidemiol. 2013; 94: 577-582.

12. Frydrysiak K, Ejdukiewicz J, Grześkowiak M. Aggression of patients and their relatives against Emergency Department Staff. Anest Ratow. 2016; 10: 46-52.

13. Petzäll $K$, Tälllberg J, Lundin T, et al. Threats and violence in the Swedish pre-hospital emergency care. Int Emerg Nurs. 2011; 19(1): 5-11, doi: 10.1016/j.ienj.2010.01.004, indexed in Pubmed: 21193162.

14. Wnukowski K, Kopański Z, Brukwicka I, et al. The dangers of medical rescue work — selected issues. Journal of Clinical Healthcare. 2015; 3: 10-16.

15. Kulczycka K, Grzegorczyk-Puzio E, Stychno E, et al. Effect of work on general wellbeing of paramedics. Medycyna Ogólna i Nauki o Zdrowiu. 2016; 22(1): 66-71, doi: 10.5604/20834543.1198726.

16. Rahimi A, Vazini H, Alhani F, et al. Relationship Between Low Back Pain With Quality of Life, Depression, Anxiety and Stress Among Emergency Medical Technicians. Trauma Mon. 2015; 20(2): e18686, doi: 10.5812/ traumamon.18686, indexed in Pubmed: 26290857.

17. Wang $F$, Zhang L, Zhang $Y$, et al. P316 Preliminary results of shift work and risk of depression: baseline data of a prospective china night shift workers cohort. Shift Work. 2016, doi: 10.1136/ oemed-2016-103951.631.

18. Karlsson B, Knutsson A, Lindahl B. Is there an association between shift work and having a metabolic syndrome? Results from a population based study of 27,485 people. Occup Environ Med. 2001; 58(11): 747752, doi: 10.1136/oem.58.11.747, indexed in Pubmed: 11600731.

19. Heckman CJ, Kloss JD, Feskanich D, et al. Associations among rotating night shift work, sleep and skin cancer in Nurses' Health Study II participants. Occup Environ Med. 2017; 74(3): 169-175, doi: 10.1136/ oemed-2016-103783, indexed in Pubmed: 27663986.

20. Wegrzyn LR, Tamimi RM, Rosner BA, et al. Rotating Night-Shift Work and the Risk of Breast Cancer in the Nurses' Health Studies. Am J Epidemiol. 2017; 186(5): 532-540, doi: 10.1093/aje/kwx140, indexed in Pubmed: 28541391.
21. Hansen AB, Stayner L, Hansen J, et al. Night shift work and incidence of diabetes in the Danish Nurse Cohort. Occup Environ Med. 2016; 73(4): 262-268, doi: 10.1136/oemed-2015-103342, indexed in Pubmed: 26889020.

22. Vetter C, Devore EE, Wegrzyn LR, et al. Association Between Rotating Night Shift Work and Risk of Coronary Heart Disease Among Women. JAMA. 2016; 315(16): 1726-1734, doi: 10.1001/jama.2016.4454, indexed in Pubmed: 27115377.

23. Binczycka-Anholcer $M$, Lepiesza P. Stress at the workplace of medical rescuer. Hygeia Public Health. 2011; 46: 455-461.

24. Garus-Pakowska A, Szatko F, Ulrichs M. Work-Related Accidents and Sharp Injuries in Paramedics-Illustrated with an Example of a Multi-Specialist Hospital, Located in Central Poland. Int J Environ Res Public Health. 2017; 14(8), doi: 10.3390/ijerph14080901, indexed in Pubmed: 28796193.

25. Parszuto J, Jaremin B, Zagozdzon P, et al. [Occupational HBV and HCV infections among health care workers]. Med Pr. 2012; 63(4): 441-452, indexed in Pubmed: 22994074.

26. Szarpak $Ł$, Kurowski A. [Do double gloves protect against contamination during cannulation of blood vessels? A prospective randomized study]. Med Pr. 2014; 65(2): 271-278, indexed in Pubmed: 25090856.

27. Yilmaz A, Serinken $M$, Dal 0 , et al. Work-related Injuries Among Emergency Medical Technicians in Western Turkey. Prehosp Disaster Med. 2016; 31(5): 505-508, doi: 10.1017/S1049023X16000741, indexed in Pubmed: 27491511.

28. Podlewski R, Płotek W, Grześkowiak $M$, et al. Carbon dioxide as a potential danger to medical rescue teams at work - A case study. Med Pr. 2017; 68(1): 135-138, doi: 10.13075/mp.5893.00408, indexed in Pubmed: 28245010.

29. Baby M, Gale C, Swain N. Communication skills training in the management of patient aggression and violence in healthcare. Aggression and Violent Behavior. 2018; 39: 67-82, doi: 10.1016/j.avb.2018.02.004.

30. Abelsson A, Rystedt I, Suserud BO, et al. Learning by simulation in prehospital emergency care - an integrative literature review. Scand J Caring Sci. 2016; 30(2): 234-240, doi: 10.1111/scs.12252, indexed in Pubmed: 26333061. 